\title{
College English Teaching Assessment System in the Era of Big Data
}

\author{
WANG Bing, YANG Yuan \\ Leshan Normal University, Sichuan, China
}

\begin{abstract}
With the rapid development of the Internet and IT (Information Technology), information explodes and evolves into many kinds of data, so China has leaped into the era of Big Data. Because of its characteristics, we can take advantage of it to create many innovations. In view of disadvantages of the traditional assessment system for the College English, it is urgent to establish the new assessment system. So this paper tries to put forward the new solution in the era of Big Data which provides us with the new angle to tackle the problem.
\end{abstract}

Keywords: College English, teaching assessment, Big Data

\section{Introduction}

The College English is one of important basic courses in colleges and universities in China which aims to develop the student's communicative skills in English. The classroom-based teaching, as the center of the whole teaching, plays a decisive role in improving the student's overall English skills. Scientific and practical teaching assessment system is not only the indispensable part of the teaching, but also the important way to improve the teaching quality. It is of great necessity to construct the teaching assessment system in order to evaluate the complex dynamic teaching process in College English course and the Big Data based on Internet offers a new possibility for the teaching assessment. Due to the features of the Big Data, this kind of teaching assessment presents the conspicuous advantages compared with the traditional one in which students, teaching instructors, and the colleagues give the assessment.

\section{The Features of Big Data}

There are four characteristics in Big Data.

\section{Big Volume}

There must be the big volume in Big Data, but this is a relative concept. In some occasions, we can regard the data we have collected as the Big Data while in another, we cannot. The volume of data varies, depending on the actual situation. So it is hard to agree on what kind of data can be regarded as the big volume. Besides it, what is most important is that the data itself should be complete. Precisely speaking, the volume refers to the huge amount of data and the complete data collections.

\section{Many Varieties}

There are many kinds of Big Data which includes network blogs, the audios, the videos, pictures and

WANG Bing, lecturer, M.A., School of Foreign Language, Leshan Normal University, Leshan, Sichuan, China.

YANG Yuan, professor, M.A., School of Foreign Language, Leshan Normal University, Leshan, Sichuan, China. 
geographic locations, etc. These kinds of data challenge the capability of processing the data. It is commonly believed that the increase of the data variety arises from the new data sources such as network blogs, social media, Internet searches, the records of cell phone communication, etc. (CHENG, 2015). In the Internet era, all the equipments integrate into a whole through the network. Personal computer users can access information through the network and become the makers and disseminators of the information. So the data explode in variety.

\section{Fast Speed}

It means the speed of data processing which is the remarkable feature different from the traditional data. In the information age, the creation and movement of data speed up. It has become a tendency to create the instant data by means of the high-speed computer processors and servers. Not only do people need know how to rapidly create data but also they should understand how to immediately cope with and analyze the data to meet the instant demand from the public.

\section{High Value}

It is the ultimate significance that the users acquire. It is some kind of insight or law that we can obtain after analyzing the data. Certainly with the wide application of Internet, it is not easy for us to dig up the really valid value from the sea of information. So how to do it through the advanced and powerful computation is the problem that needs solving without any delay.

\section{The Disadvantages of the Traditional Teaching Assessment System}

Teachers focus on student's vocabulary accumulation and the grammar knowledge in the traditional English teaching, so in the classroom, the teachers are the dominators who are the center of the whole teaching. Thus the teaching evaluation is mainly to evaluate the teacher's teaching skills. The purpose of the assessment is to see whether the teachers have the basic skills to take up the teaching. Generally speaking, the problems are as follows in the traditional teaching assessment system.

\section{To Emphasize the Evaluation From the Experts and Colleagues and Ignore the Teacher's Self-evaluation}

In the traditional teaching assessment system, the assessment team including the experts and colleagues evaluates the teaching in the classroom regularly or at random, giving the scores according to some assessment indicators. After one period of teaching, the advantages and disadvantages of the teaching are listed by the assessment team. The teachers themselves do not get involved in the assessment before or after the teaching. In terms of the purpose of the assessment, it just aims to check the teacher's basic teaching ability or to rank the teachers in the teaching contest. In this way, the teachers maybe learn from each other and improve their teaching in a way, but it has a very limited effect due to the diversion of the purpose.

\section{To Evaluate the Teaching Just From One Dimension}

The teaching in the class is often measured through the scores given by the experts and colleagues, which is just the quantitative assessment. The qualitative assessment such as the way of interview, observation, documentation, etc., is often ignored. The teacher's teaching ability is inclined to be judged just by one kind of assessment, without taking into account the external factors such as the teacher's emotions, the preparation, the student's state of mind, etc. So we should regard the teaching assessment as a continuous process and keep track of the teaching improvement made by the teacher through documentation. But no matter what kind of assessments or both of them are used, the result of the evaluation will not be the same on account of the 
different assessment philosophy held by the evaluators, which is not beneficial to the improvement of teaching quality. Thus, we should focus on the researches on the scientific and rational assessment philosophy in the College English teaching assessment system with which the teaching quality can be enhanced

\section{The Principles of Establishing New Teaching Assessment System}

\section{To Diversify the Assessment Participants and Assessment Targets}

The teaching in the classroom is a mutual process in which teachers and students can help each other, but the students are the main party who conduct the learning activities and their learning represents the teaching effect from teachers. So they play a major role in evaluating the teaching in the classroom. The teachers organize and carry out the teaching process in the classroom. So their knowledge of the teaching objectives is also used as a tool for the assessment. So in addition to the students, colleagues, and teaching administrators, the teacher also should be included in the list of assessment participants. The evaluation will be more objective and comprehensive by combining the assessments from many participants, which can push teachers to improve their teaching (LIU, 2007). As for the assessment targets, the traditional assessment lays the emphasis on the teacher's teaching attitude, teaching abilities and teaching contents, etc. But in the classroom-based teaching, the students are not only the passive receivers but also the active constructers in the knowledge (Nunan, 2001). In addition, the teaching effect depends on the students' involvement in terms of their behaviors, emotions, and active conception of the teaching process in some way. So in order to know the real teaching effect, not only teachers but also students should be included in the list of the teaching assessment targets (see Table 1).

\section{Qualitative Evaluation as a Major Role and Quantitative Evaluation as a Minor Role}

Quantitative evaluation can be used to keep the exact tract of the teacher's and student's behaviors in the teaching process in the classroom through mathematics to reveal the potential relations and regular patterns between a variety of behaviors. But the important qualities in the teaching tend to be neglected in quantitative evaluation which are hard to be quantified. The qualitative evaluation focuses on the consistence between the teaching results and the education objectives. It lays emphasis on the investigation of the teaching strength and weakness. The evaluation mechanics should be more substantial. Through it, the complete teaching process can be described and recorded as it is and the evaluation result is more specific, authentic, and has a more direct effect on the teacher's and student's feedbacks. Both qualitative evaluation and quantitative evaluation can make the teaching assessment more comprehensive. The abundant information offered by Big Data such as the statistics, words, the audios, the videos, and pictures, the communication emails between teachers and students, and the messages in the discussion section makes it possible to combine both of the evaluations.

\section{The New College English Teaching Assessment System}

The College English teaching is guided by the teachers and aims to develop the student's overall English ability through the interactions between students and teachers and the student's self-learning. Therefore, the teaching assessment should evaluate the teachers' activities and student's activities, which is the main part (YU, 2008). According to the characteristics of College English teaching, qualitative evaluation and quantitative evaluation are adopted.

\section{Quantitative Evaluation}

It means to get the general impression about a lesson by means of assessing the index. The people who 
give the assessment include experts, teachers, and students. The expert's assessment and teacher's assessment should contain all the evaluation about all the items. The student's assessment should include their own learning attitude, the involvement level, the learning ways, and learning effect. That is to say, the assessment is about their own learning experiences and learning results in the classroom.

Table 1

Quantitative Evaluation of New College English Teaching Assessment System

\begin{tabular}{|c|c|c|c|c|c|c|c|}
\hline \multirow{2}{*}{$\begin{array}{l}\text { Assessment } \\
\text { target }\end{array}$} & \multirow{2}{*}{\multicolumn{2}{|c|}{ Assessment indicators }} & \multicolumn{5}{|c|}{ Score } \\
\hline & & & 5 & 4 & 3 & 2 & 1 \\
\hline \multirow{7}{*}{$\begin{array}{l}\text { Assessment } \\
\text { given to the } \\
\text { teachers }\end{array}$} & \multirow{2}{*}{ Teaching objectives } & Language knowledge and the ability to use it & & & & & \\
\hline & & Knowledge, emotion, and attitude & & & & & \\
\hline & \multirow{3}{*}{ Teaching methods } & Paying attention to the characteristic of the language & & & & & \\
\hline & & Choosing the proper teaching media & & & & & \\
\hline & & Suitable for the students' language competence & & & & & \\
\hline & \multirow[t]{2}{*}{ Teaching design } & The best way to achieve the teaching objectives & & & & & \\
\hline & & Reasonable arrangement of time for each teaching phases & & & & & \\
\hline \multirow{12}{*}{$\begin{array}{l}\text { Assessment to } \\
\text { the students }\end{array}$} & \multirow{2}{*}{ Learning attitude } & Focusing on the current tasks & & & & & \\
\hline & & Being enthusiastic and explorative about the learning & & & & & \\
\hline & \multirow{3}{*}{$\begin{array}{l}\text { The level of } \\
\text { participation }\end{array}$} & $\begin{array}{l}\text { Be ready to do exercises about listening, speaking, reading, } \\
\text { and writing }\end{array}$ & & & & & \\
\hline & & Be willing to do the task-based exercises & & & & & \\
\hline & & Be ready to apply their learning to daily social activities & & & & & \\
\hline & \multirow{3}{*}{ Learning approach } & $\begin{array}{l}\text { Adopting the proper approaches according to the learning } \\
\text { content }\end{array}$ & & & & & \\
\hline & & Be able to study on their own & & & & & \\
\hline & & Paying attention to the practice and applications & & & & & \\
\hline & \multirow{4}{*}{ Learning effect } & The achievement of the task in the class & & & & & \\
\hline & & Satisfaction with the learning atmosphere & & & & & \\
\hline & & Satisfaction with the learning results & & & & & \\
\hline & & Satisfaction with the learning methods & & & & & \\
\hline
\end{tabular}

\section{Qualitative Evaluation}

The College English course is to develop the student's English ability in listening, speaking, reading, writing, and translation to make them be able to communicate effectively with native speakers in the authentic situation by making use of the language knowledge they have learned. Thus, the most important evaluation is to assess the teacher's and students' behaviors which are not through the standardized test and the written exams, but through the observations, recordings, teamwork, experiments, performances, demonstrations and speeches, etc. The teachers and students can analyze the information from the real situations to enhance the teaching and learning.

\section{Conclusion}

We are now in the era of Big Data and we should take advantage of it to reform the traditional College Teaching assessment system which is now more or less disappointing because of its many disadvantages, for example, the evaluation participants are not diversified and the assessment targets are not appropriate. What is more, the evaluation methods are not to the point. Because of the characteristics of Big Data, we can establish a new College English teaching assessment system by means of diversifying the assessment participants and 
making use of the qualitative assessment and quantitative assessment based on the data collections offered by Big Data. It is promising that the teaching quality can be enhanced through this kind of teaching assessment system.

\section{References}

CHENG, J. L. (2015). MOOC in Big Data and foreign language research. Shanghai: Computer-Assisted Foreign Language Teaching.

LIU, J., \& ZENG, X. (2007). On the evaluation system of college English classroom-teaching. Beijing: China Foreign Language.

Nunan, D. (2001). The learner-centered curriculum: A study in second language teaching. Shanghai: Shanghai Foreign Language Education Publish House.

YU, G. (2008). The exploration of multi-evaluation system in college English teaching. Beijing: China Higher Education Research. 